\title{
BMJ Open Health and economic benefits of reducing sugar intake in the USA, including effects via non-alcoholic fatty liver disease: a microsimulation model
}

\author{
Rick A Vreman, ${ }^{1}$ Alex J Goodell, ${ }^{1}$ Luis A Rodriguez, ${ }^{2}$ Travis C Porco, ${ }^{2,3}$ \\ Robert H Lustig, ${ }^{1,4}$ James G Kahn ${ }^{1}$
}

To cite: Vreman RA, Goodell AJ, Rodriguez LA, et al. Health and economic benefits of reducing sugar intake in the USA, including effects via non-alcoholic fatty liver disease: a microsimulation model. BMJ Open 2017;7:e013543. doi:10.1136/ bmjopen-2016-013543

- Prepublication history and additional material for this paper are available online. To view these files please visit the journal online (http://dx.doi. org/10.1136/bmjopen-2016013543).

Received 28 July 2016 Revised 20 June 2017 Accepted 21 June 2017

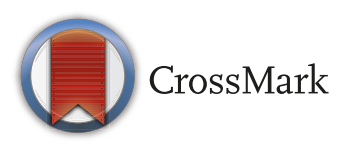

${ }^{1}$ Philip R. Lee Institute for Health Policy Studies, University of California San Francisco, California, USA

${ }^{2}$ Department of Epidemiology \& Biostatistics, University of California, San Francisco, California, USA

${ }^{3} \mathrm{FI}$ Proctor Foundation for Research in Ophthalmology, University of California, San Francisco, California, USA

${ }^{4}$ Department of Pediatrics, University of California San Francisco, San Francisco, California, USA

Correspondence to

Rick A Vreman;

r.a.vreman@gmail.com

\section{ABSTRACT}

Objectives Excessive consumption of added sugars in the human diet has been associated with obesity, type 2 diabetes (T2D), coronary heart disease (CHD) and other elements of the metabolic syndrome. Recent studies have shown that non-alcoholic fatty liver disease (NAFLD) is a critical pathway to metabolic syndrome. This model assesses the health and economic benefits of interventions aimed at reducing intake of added sugars.

Methods Using data from US National Health Surveys and current literature, we simulated an open cohort, for the period 2015-2035. We constructed a microsimulation model with Markov chains for NAFLD (including steatosis, non-alcoholic steatohepatitis (NASH), cirrhosis and hepatocellular carcinoma (HCC)), body mass index, T2D and $\mathrm{CHD}$. We assessed reductions in population disease prevalence, disease-attributable disability-adjusted life years (DALYs) and costs, with interventions that reduce added sugars consumption by either $20 \%$ or $50 \%$.

Findings The model estimated that a $20 \%$ reduction in added sugars intake will reduce prevalence of hepatic steatosis, NASH, cirrhosis, HCC, obesity, T2D and CHD. Incidence of T2D and CHD would be expected to decrease by 19.9 (95\% Cl 12.8 to 27.0$)$ and $9.4(95 \% \mathrm{Cl} 3.1$ to 15.8$)$ cases per 100000 people after 20 years, respectively. A $20 \%$ reduction in consumption is also projected to annually avert 0.767 million (M) DALYs $(95 \% \mathrm{Cl} 0.757 \mathrm{M}$ to $0.777 \mathrm{M})$ and a total of US $\$ 10.3$ billion $(\mathrm{B})(95 \% \mathrm{Cl} 10.2 \mathrm{~B}$ to $10.4 \mathrm{~B}$ ) in discounted direct medical costs by 2035 . These effects increased proportionally when added sugars intake were reduced by $50 \%$.

Conclusions The decrease in incidence and prevalence of disease is similar to results in other models, but averted costs and DALYs were higher, mainly due to inclusion of NAFLD and CHD. The model suggests that efforts to reduce consumption of added sugars may result in significant public health and economic benefits.

\section{INTRODUCTION}

The social and economic burdens of chronic metabolic disease have been increasing in the USA for the last 3 decades. Two-thirds of the adult population in the USA is now overweight, and morbid obesity affects $9.9 \%$
Strengths and limitations of this study

- This model captures the full effects of dietary sugar acting on non-alcoholic fatty liver disease, as well as obesity, type 2 diabetes and coronary heart disease.

- The model is based on input parameters from multiple studies that were of mixed quality and alignment with the modelled population. We examined large uncertainty intervals to assess robustness of results.

- The model does not consider a shift to non-sugared caloric foods.

of all adult women. ${ }^{1}$ Prevalence of type 2 diabetes (T2D) in the USA is at $9.3 \%,{ }^{23}$ and the population affected by coronary heart disease (CHD) increased concurrently from 13 to 15.5 million over the last 10 years. $^{45}$ More than $15 \%$ of all deaths are attributable to CHD and more than $3 \%$ to diabetes. ${ }^{6}$ Costs have simultaneously increased, and costs for CHD are expected to double over the next 2 decades. $^{78}$ Though these figures are stunning, they underestimate the magnitude of the problem. Non-alcoholic fatty liver disease (NAFLD) has recently been found to be present in over $45 \%$ of Latinos, 33\% of Caucasians and $24 \%$ of African-Americans and is thought to play an important role in metabolic pathophysiology. ${ }^{9-12}$ NAFLD is defined by the presence of liver fat in the absence of a primary insult such as alcohol, viral hepatitis or heavy metal accumulation. ${ }^{13}$ NAFLD is further categorised into: (a) hepatic steatosis, which is a reversible fat accumulation in the liver defined by an occupation of steatotic hepatocytes of more than $5 \%$ of the liver parenchyma; and (b) non-alcoholic steatohepatitis (NASH), which is defined as the presence of hepatic steatosis along with lobular and portal inflammation with hepatocyte injury (ballooning). Progressive collagen 
deposition and vascular remodelling in NASH may lead to cirrhosis, which in turn predisposes one to hepatocellular carcinoma (HCC).$^{913-15}$ NAFLD is the most common cause of liver disease in the Western world, and NASH is projected to become the leading cause of liver transplantation in the USA by the year $2020 .{ }^{16}{ }^{17}$ Currently, $30 \%-40 \%$ of patients with NASH-cirrhosis succumb to a liver-related death within 10 years. ${ }^{18}{ }^{19}$ Hospitalisations for NAFLD have increased $97 \%$ between 2000 and 2012. ${ }^{20}$ NAFLD has also been suggested as an important driver of T2D in lean individuals, as liver fat accumulation can cause insulin resistance. ${ }^{1021-23}$ NAFLD can occur as either a cause or consequence of the metabolic syndrome, ${ }^{10}$ and many now argue that NAFLD is the hepatic manifestation of metabolic syndrome and should be included in its definition. ${ }^{24-27}$ It is important to identify determinants of these metabolic diseases and assess the efficacy of upstream policy interventions to curb the national and the global epidemic of metabolic syndrome.

\section{Added sugars}

Added sugars consumption increased in the USA over the years 1977-2000, decreased slightly between 2000 and 2008 and seems to have stabilised in the years thereafter. $^{28-30}$ Over $55 \%$ of all American adults consumed more than $50 \mathrm{~g}$ added sugars per day between 2005 and 2012, which is thought to be the cut-off value for added risk of metabolic derangement and more than the advised maximum according to the American Heart Association (AHA) (25-37.5 g). ${ }^{3} 31$ The US Department of Agriculture recently established guidance for an upper limit of consumption of added sugars at $10 \%$ of total energy intake (amounting to $50 \mathrm{~g}$ per day $(200 \mathrm{kcal})$ for a prototype $2000 \mathrm{kcal} /$ day diet) ${ }^{32}$ The European Food and Safety authority does not state an explicit maximum for (added) sugars in their advice, but they do note that a number of authorities have established boundaries of $<10 \%$ of total energy intake. ${ }^{33}$ Furthermore, the AHA recommends that US adolescents restrict their intake of added sugars to less than $25 \mathrm{~g}$ to avoid dyslipidaemia and CVD, ${ }^{34}$ yet current intake averages $94.0 \mathrm{~g}$ per day in this age group. ${ }^{35}$

The excessive amount of added sugars (glucose+fructose) in the food supply has been associated with NAFLD and with each of the component diseases of the metabolic syndrome. ${ }^{36-38}$ Fructose is metabolised by the liver, as it is the only organ with the required Glut 5 transporter. Fructose bypasses glycogen and is metabolised by the glycolytic pathway to acetyl-CoA. From there, excess acetyl-CoA is converted to citrate, diverted from the mitochondria into the cytoplasm via the citrate shuttle and is then converted into fatty acids through the process of de novo lipogenesis (DNL). ${ }^{39}$ From there, hepatically derived excess triglyceride is either packaged with apo-B100 into very-low-density lipoprotein, which is released into the bloodstream and can foment cardiovascular disease, or will precipitate as a lipid droplet, resulting in hepatic steatosis, which drives insulin resistance, causing weight gain, and predisposing to T2D. While most early studies of added sugar and chronic disease were correlative and confounded by excess caloric administration, lack of adjustment for total calories or adiposity, more recent studies demonstrate that the effect is specific for dietary fructose and independent of calories consumed and body mass index (BMI) ${ }^{39-48}$ For instance, added sugar is directly correlated with risk for metabolic syndrome in adolescents in the National Health and Nutrition Examination Survey (NHANES) even after controlling for total calories and BMI z-score. ${ }^{35}$ Added sugar has been associated with elevated uric acid levels and hypertension. ${ }^{49} 50$ Two recent studies, both controlled for calories and adiposity and employing a time analysis, support sugar-sweetened beverages (SSBs) as a specific causative agent in the pathogenesis of T2D. ${ }^{42} 5152$ A decade-long global econometric analysis demonstrates that only changes in sugar availability are predictive of changes in diabetes prevalence, unrelated to poverty, urbanisation, ageing, physical activity, total calories or obesity. ${ }^{37}$ Lastly, in a starch-forsugar exchange study, improvements in metabolic and lipid parameters unrelated to both calories and changes in weight were documented, demonstrating improved metabolic health within 10 days. ${ }^{40} 53$ We have demonstrated that the decline in DNL and resultant reduction in liver fat was the primary driver in the metabolic and cardiovascular improvement. ${ }^{54}$ By demonstrating that removal of dietary fructose (the macronutrient most closely associated with DNL) commensurately improves liver fat and insulin dynamics irrespective of calories or weight, we are able to infer a causative mechanism of metabolic dysfunction by linking DNL to both liver fat and insulin resistance. We also demonstrated that despite an increase in the glucose (starch) content of the diet, betacell insulin secretion reduced, thus protecting against beta-cell exhaustion, thought to be important in the pathogenesis of T2D ${ }^{55}$ and reducing total body insulin burden, thought to contribute to both obesity and risk for cardiovascular disease. ${ }^{56}$ Thus, reduction in DNL and liver fat through reduction in consumption of added sugars appears to be a primary goal of both therapy and prevention of chronic metabolic disease and forms the rationale for our microsimulation model.

\section{Intervention efficacy}

Several studies have modelled the effects of different interventions to reduce added sugars intake. One popular intervention is the implementation of an SSB tax. Though this does not affect all added sugars in the food supply, SSBs are the main single contributor to overall added sugars intake, and a tax on SSBs is easier to implement than an added sugars tax. ${ }^{58}$ A $20 \%$ SSB tax is projected to reduce prevalence of obesity anywhere from $1.5 \%$ to $10 \%$, based on different studies ${ }^{59-61}$ Data from Mexico demonstrate that effects on reduction of consumption are durable, although evidence of mitigation of disease is not yet available. ${ }^{62}$ Annual diabetes cases would be expected to decline concurrently between $1.8 \%$ and $3.4 \%$ and CHD cases by $0.5 \%-1.0 \%{ }^{60}{ }^{63}$ Additional 
research has focused on other strategies to lower added sugars consumption. Banning SSBs from the US Supplemental Nutrition Assistance Program is expected to result in a $0.89 \%$ lower obesity prevalence within 10 years, while lowering the amount of sugars in the food supply through a cap-and-trade approach by $1 \%$ annually is expected to lower the prevalence of obesity by $1.7 \%$ after 20 years. ${ }^{6465}$

An important limitation of all these studies is that none of these models incorporate the effects and costs related to sugar-induced NAFLD. Because NAFLD explains a part of the incidence of diabetes in lean individuals and is expected to contribute significantly to overall healthcare burden and costs, it is necessary that models incorporate all of these diseases.

Our goal is to predict the magnitude of the health and economic effects of interventions that are designed to reduce added sugars consumption either by $20 \%$ or $50 \%$, respectively. This modelling approach more precisely quantifies the benefits of reducing added sugar consumption. We describe the process of creating, calibrating and validating a microsimulation model. We clarify the relevant interactions that determine progression within this model in Markov chains for NAFLD (including cirrhosis and HCC), obesity, T2D and CHD, and we describe the creation of a simulated open cohort representative of the US population. We allow the model to run for 20 years into the future to predict effectiveness. We report the outcomes of these simulations in future incidence, prevalence and mortality of disease and in disability-adjusted life years (DALYs) and costs averted.

\section{METHODS}

The Methods section is constructed according to the recommendations by the International Society For Pharmacoeconomics and Outcomes Research taskforce for good modelling practice, and completeness is checked according to the Consolidated Health Economic evaluation Reporting Standards statement. ${ }^{6667}$

\section{Summary}

We constructed an individual-based model consisting of a base cohort of 22400 people. New people entered the model each year at age 20, the youngest age group we simulate. Individuals are assigned a state at initialisation in each 'chain' of the model. These include age, sex, ethnicity, sugar consumption, NAFLD, BMI, T2D and CHD. The current health state of each individual at the beginning of a cycle forms a risk profile, and the presence in a risk-inducing state in one of the chains can influence the probability of transitioning between states in a different chain, according to literature-based odds ratios (ORs). We simulated 20 annual cycles for each individual, counting events, incurred direct medical costs and DALYs for each cycle, as well as the overall prevalence for the total cohort. We discounted the costs and DALYs by $3.0 \%$ annually, and costs were presented in 2015 US\$. Two interventions were simulated: one that reduced each individual's added sugars consumption by $20 \%$ and one that reduced it by $50 \%$. We used identical random numbers for the base case scenario and each of the interventions, to reduce variance. We calibrated the model to other studies reporting historic trends and predicting future prevalence and validated the model via face validation, cross-validation and sensitivity analyses. Deterministic sensitivity analysis was used to determine the influence of individual input parameters. Probabilistic sensitivity analysis was used to generate mean results and $95 \%$ central coverage intervals.

\section{Model type}

An individual-based stochastic Markov model (microsimulation) was used. The model contained a chain for each of four separate diseases. Because each of these diseases has a minimum of three states and the transitions between these states are based on the presence or absence of a set of risk factors, the state-space explosion phenomenon prohibits us from using traditional Markov cohort simulation. An individual-based approach makes it possible to use individual-specific transition rates, capturing the effect of interventions on individual risk factor profiles, thereby avoiding the need to count the number of individuals in all possible states and allowing for complex relationships between several risk factors within a single individual. ${ }^{68}$ It also opens up potential for future analyses among subgroups.

\section{Population and setting}

The model is based on the adult population (age 20+) of the USA. Outcomes are reported from a healthcare perspective. This includes direct medical costs and DALYs averted. Indirect medical or non-medical costs are excluded. Because this model is meant to assess the benefits of reducing added sugars intake, unrelated to the type of intervention, costs of implementing any specific intervention and possible revenues (eg, in the case of an excise or general services tax) are also excluded.

\section{Model structure and input parameters}

A simplified model transition diagram is presented in figure 1. Model input parameters are presented in tables 1 and 2 and online supplementary table 1 . Individuals will reside in a state within each chain at any given point in time. The probability of staying within a state or moving to another state in each cycle is determined by a set of defined transition probabilities, which are influenced by the risk profile (the current state in the other chains) of the individual. Events in different chains can occur in parallel.

The simulation is initialised by assignment of age (A), sex (S) and ethnicity (E) to each individual. Age states are based on the population distribution that is provided by the Bureau of the Census and are specified for each age from 20 to 84 and a cumulative age group for anyone above 85 . We simulate an open cohort. New individuals with age 20 enter each year. ${ }^{69}$ The initial age distribution is specified in online supplementary table 2. Male and female sexes are incorporated with an initial 


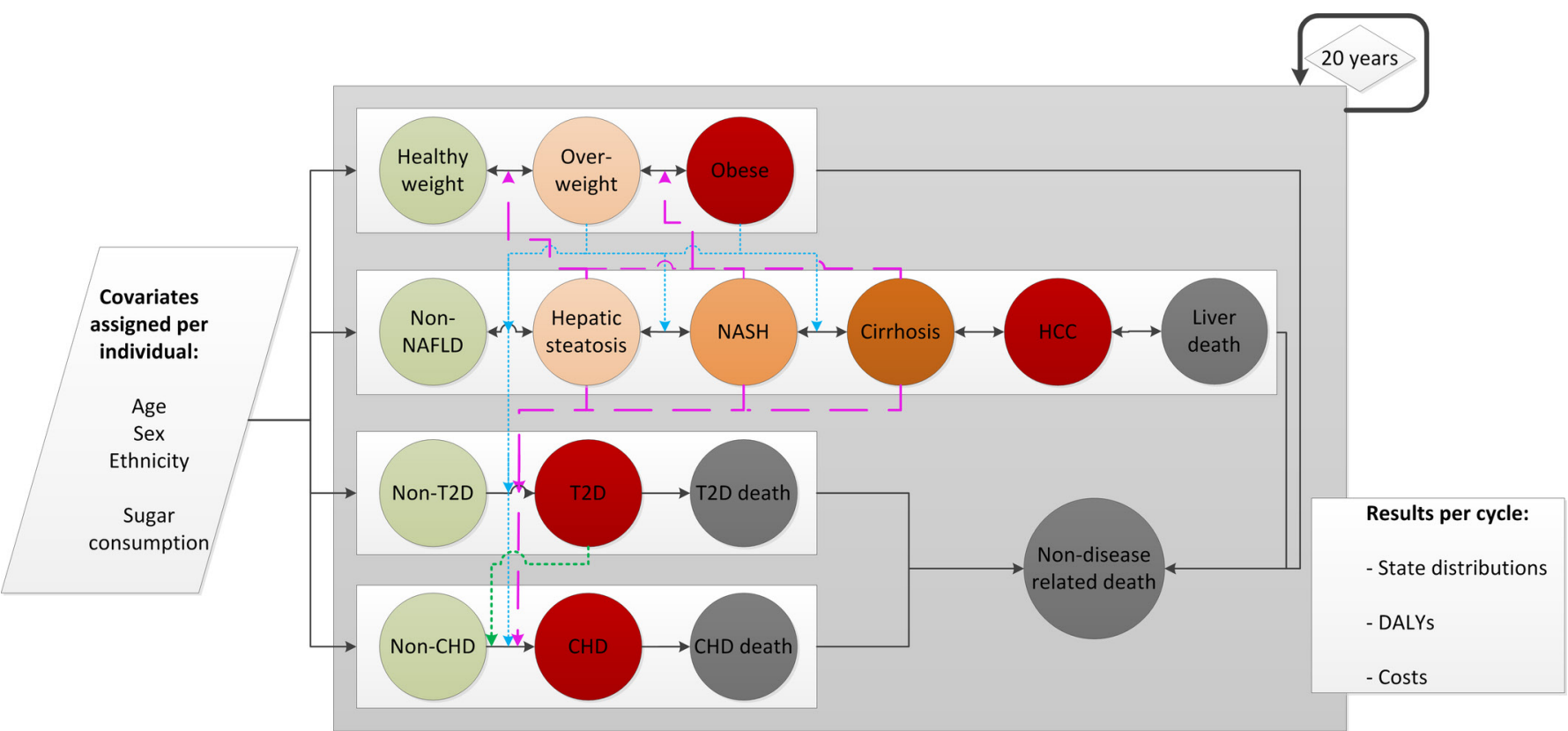

Figure 1 Model state and covariate structure. Each individual gets assigned a state in each chain at the start of the simulation and their specific covariates (age, sex, ethnicity, high/low sugar consumption). Circles represent disease states. Solid lines indicate a possible transition pathway between states. Coloured lines indicate how being in a state within one chain can affect the value of the transition probability between two states in another chain. These are split into three categories: pink striped lines indicate the effect of NAFLD on progression in the BMI, T2D and CHD chains. Blue dotted lines indicate the effect of overweight and obesity on progression in the NAFLD, T2D and CHD chains. The green dotted line indicates the effect of T2D on progression in the CHD chain. Three chains contain disease-related deaths, and the model contains a non-disease-related death state for other causes of mortality. The states of individuals are updated every cycle (ie, annually) for 20 years. Each cycle, the state distributions and their related costs and DALYs are generated as output. CHD, coronary heart disease; DALY, disability-adjusted life year; HCC, hepatocellular carcinoma; NAFLD, non-alcoholic fatty liver disease; NASH, non-alcoholic steatohepatitis; T2D, type 2 diabetes.

distribution specified in online supplementary table 3 . Ethnicities incorporated into the model are Hispanic, non-Hispanic black and non-Hispanic white. Data availability did not allow us to incorporate Asians and Native Americans as separate groups, and therefore, they were grouped with the non-Hispanic whites. The initial ethnicity distribution is specified in online supplementary table 4.

When the individual is assigned an age, sex and ethnicity, these determine the state that this individual will be assigned to in each of the chains for NAFLD, BMI, T2D and CHD at the start of the simulation. Each chain represents a separate disease process and has its own non-disease state (eg, non-T2D). This does not mean that this person is actually healthy (eg, a person can have cirrhosis but not diabetes). The NAFLD chain includes a non-NAFLD state and states for hepatic steatosis, NASH, cirrhosis and NASH-related or cirrhosis-related HCC. A person is defined as having NAFLD when his or her current state is steatosis, NASH or cirrhosis. This is different from common terminology, where cirrhosis is excluded. We chose this definition for easy reference because these three states imply extra risk for progression within other chains. The initial distribution over NAFLD states is specified in online supplementary table 5 and specified per ethnicity group.
It is important to note that modelled cirrhosis and HCC are specifically related to steatosis and NASH and do not include all cirrhosis and HCC cases within the population, irrespective of cause. Transition directly from the non-NAFLD state to either one is therefore not possible. Baseline transition probabilities are specified in table 2, and transition rates from NASH and cirrhosis to HCC are specified per age group, as defined in online supplementary tables 6 and 7 , starting at age 40 (age groups: 40-44, 50-54, 55-59, 60-64, 65-69, 70-74, 75-79 and 80 years and over). Risk factors for progression are stated in table 2 and include ethnicity (protective and detrimental factors), being overweight or obese and high sugar consumption. These risk factors apply for transitions up to the cirrhosis state.

The BMI chain includes states for healthy weight, overweight and obesity. The initial distribution over BMI states is specified in online supplementary table 8 and specified by sex, ethnicity and age group (ages 20-35, 35-44, 45-54, 55-64, 65-74, 75-84 and 85+). Baseline transition probabilities are specified in table 2. Risk factors for progression are stated in table 1 and include NAFLD disease states and high sugar consumption.

The T2D chain includes a non-T2D state and a T2D state. The initial distribution over T2D states is specified in online supplementary table 9 and specified by 


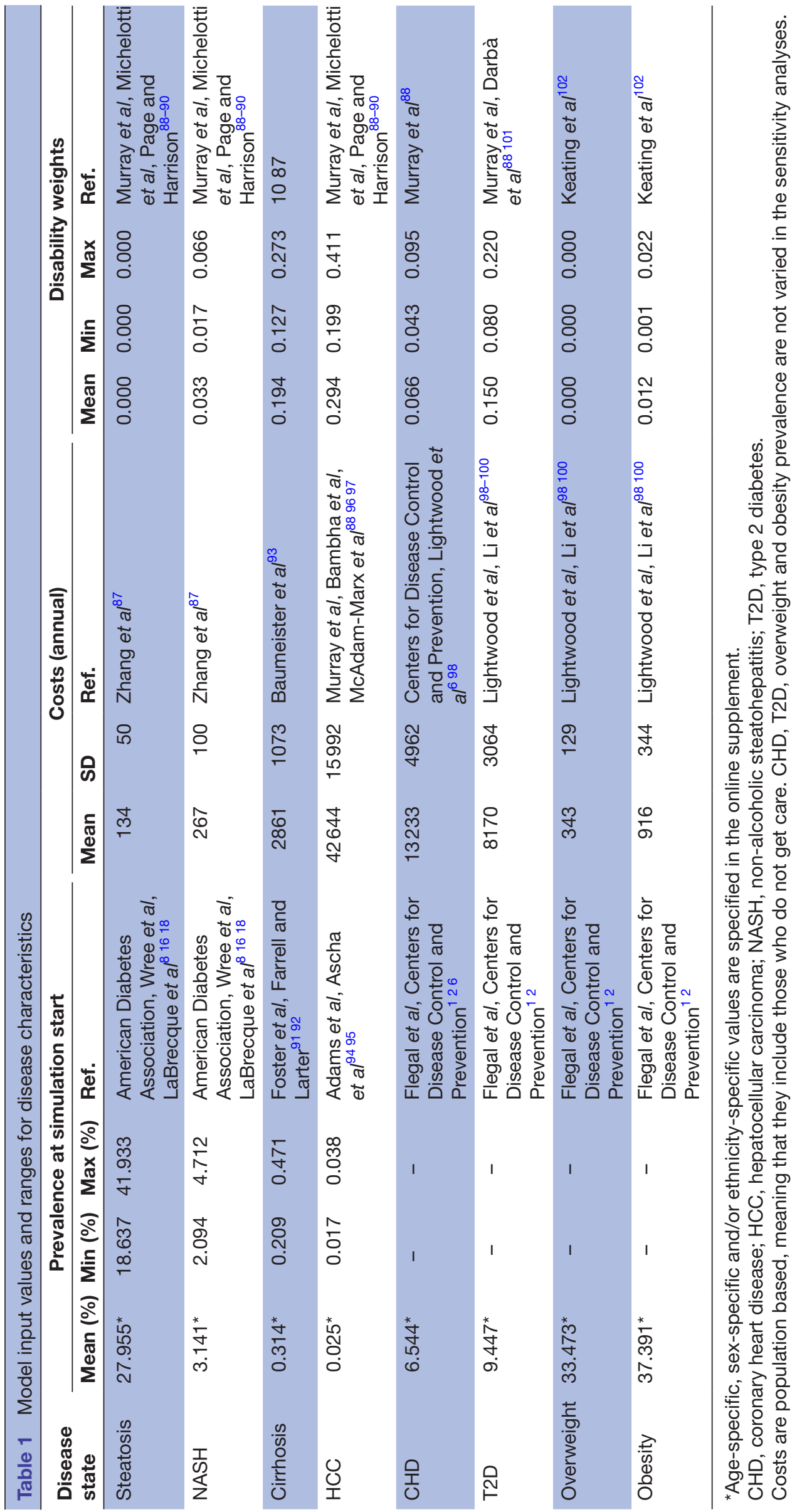




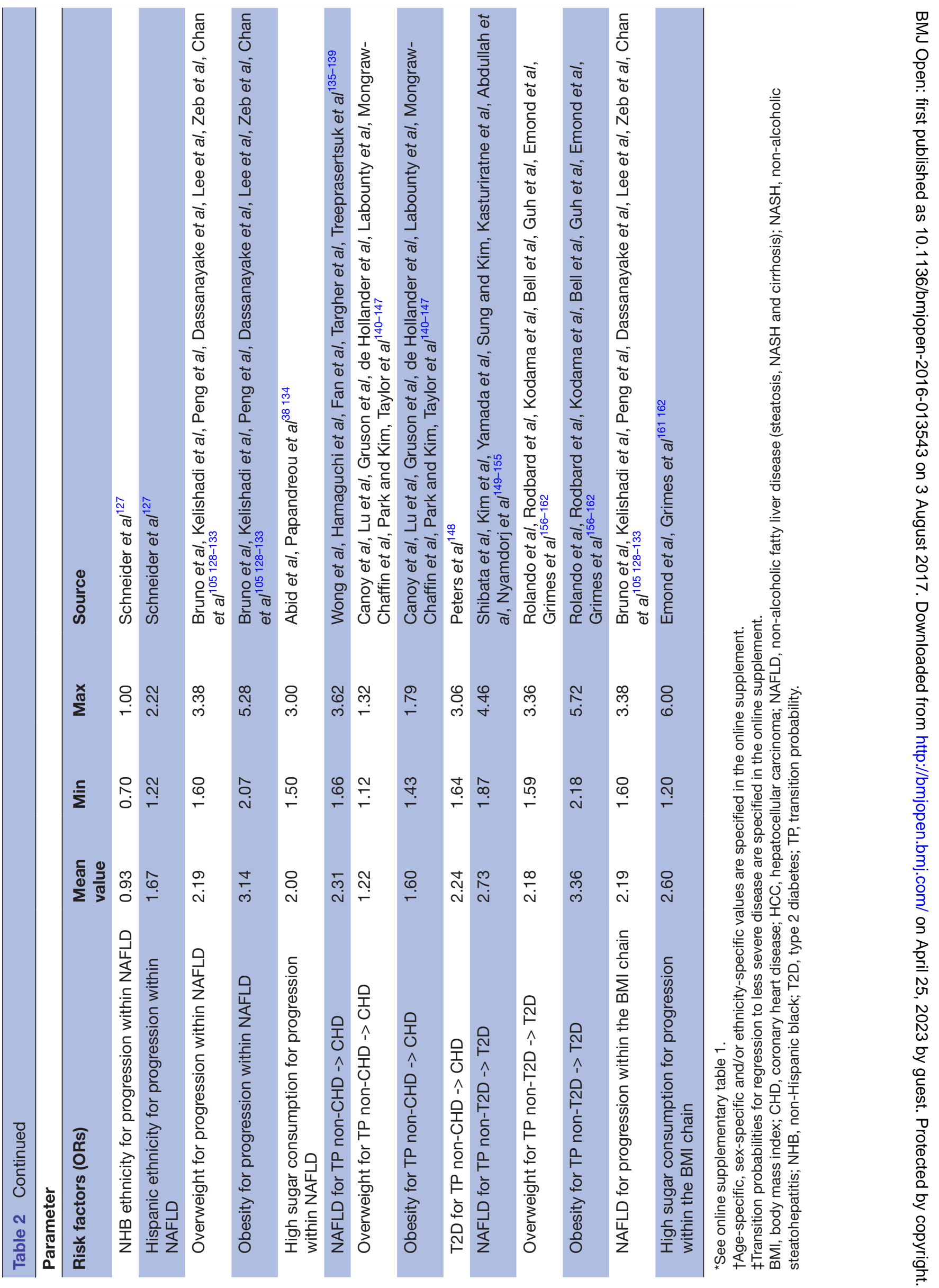


sex, ethnicity and age group (ages 20-35, 35-44, 45-54, 55-64, 65-74, 75-84 and 85+). Average baseline transition probability to T2D is specified in table 2, and age-specific incidence rates are provided in online supplementary table 10 (age groups: 20-24, 25-29, 30-34, 35-39, 40-44, 45-49, 50-54, 55-59, 60-64, 65-69, 70-74, 75-79 and $80+)$. Risk factors for progression to T2D are stated in table 2 and include NAFLD disease states, overweight and obesity.

The CHD chain includes a non-CHD state and a CHD state. The distribution over CHD states at simulation start is specified in online supplementary table 11 and specified per sex, ethnicity and age group (ages 20-44, 45-64 and $65+$ ). Average baseline transition probability to CHD is specified in table 2 , and age-specific incidence rates are provided in online supplementary table 12 (age groups: $<35,35-39,40-44,45-49,50-54,55-59,60-64,65-69$, $70-74,75-79,80-84$ and $85+)$. Risk factors for progression to CHD are stated in table 2 and include NAFLD disease states, overweight, obesity and T2D.

Each individual is assigned a level of consumption of added sugars. There are two states in the sugar chainhigh consumption ( $\geq 50 \mathrm{~g}$ added sugars per day) and low consumption $(<50 \mathrm{~g}$ added sugars per day). The distribution of these states among the study population reflects the data of the NHANES 2005-2012 and is specified per sex and ethnicity group, as shown by online supplementary table $13 .{ }^{3}{ }^{35}$ Dietary intake data in NHANES were collected using two 24-hour dietary recalls, following the United States Department of Agriculture's (USDA) Automated Multiple Pass Method and administered to the adult. ${ }^{70}$ The arithmetic mean of added sugar intake in grams per day was obtained by merging individual dietary recalls from NHANES with the USDA Food Patterns Equivalents Database. ${ }^{71}$ Sugar consumption is fixed throughout the simulation for each person.

From each state, individuals can transition to a 'non-disease-related death' state. Three disease chains also have a disease-specific death state (ie, T2D death, CHD death and liver-related death), allowing calculation of disease-attributable death. Mortality rates from causes outside the model were corrected for the competing risks of modelled causes of mortality to ensure valid overall mortality. Death in one chain forces an instant transition to the death state in other chains. Average transition probabilities to disease-related death states are specified in table 2. Age-specific rates for T2D-related death are specified in online supplementary table 14 . Liver death rates are specified in table 2. Deaths were attributed to the disease for which the transition to death was established first. To remove confounding because of calculation order, chain calculation order was randomised. This ensures that deaths are attributed to the right disease (eg, people with T2D and CHD have a chance to die of T2D or CHD or succumb to a non-disease-related death).

To determine whether there were temporal trends in incidence or death rates, we plotted the available historic data (1999-2013) and projected this to the future. ${ }^{5672}$
These trends were found to be present for the incidence and mortality rate of CHD and for the non-disease-specific mortality rate. We incorporated these regression rates into the model by adjusting the respective baseline transition probabilities before each cycle. Average baseline transition probabilities for CHD and non-disease-related deaths are specified in table 2. The CHD-specific death rates by year and age are specified in online supplementary table 15 , and the non-disease-related death rates per year and age are specified in online supplementary table 16. For DALY calculations, health-adjusted life expectancy for females and males is provided in online supplementary tables 17 and 18 .

Final transition probabilities per chain are compared with a pseudo-random number to determine state-transitions each cycle. These final transition probabilities were derived from baseline transition probabilities, adjusting for the relative risk of progression observed for applicable risk factors. The correction formula for the baseline transition probabilities is a multiplicative function of all applicable values (ORs) for present risk factors. As an example, imagine a person with high sugar consumption, obesity and hepatic steatosis but no T2D or CHD (disregarding age, sex and ethnicity in this example). In the NAFLD chain, the transition from steatosis to NASH has a baseline transition probability of 0.0060 (see table 2 ). This is adjusted to reflect the ORs for applicable risk factors (3.14 for obesity and 2.00 for high sugar consumption), resulting in a revised transition probability of $0.0060 \times 3.14 \times 2.00=0.0377$. Similar adjustments are made for transitions to cirrhosis, HCC, death and non-NAFLD. What remains is the probability of remaining in the steatosis state.

\section{Interventions}

Two interventions were simulated: a reduction of $20 \%$ and a reduction of $50 \%$ in individual added sugars consumption. A $20 \%$ reduction in added sugars was simulated to be consistent with the percentage reduction assessed in several studies. ${ }^{59-61}$ In addition, a $50 \%$ reduction was simulated because AHA advises 6-9 teaspoons of added sugar (for females and males, respectively) as a maximum per day, which is approximately $50 \%$ of the current average consumption. ${ }^{3135}$ The individual added sugars consumption distribution was then split into a dichotomous variable, with people consuming less than or equal to $50 \mathrm{~g}$ added sugars being considered low consumers and people consuming more than $50 \mathrm{~g}$ per day being considered high consumers. This model did not incorporate substitutions to other food categories, but it did incorporate the overall added sugars reduction rather than a sole reduction in SSB consumption used in other studies. ${ }^{6063}$ This makes it possible to capture the overall effects of added sugars, contrary to the solitary effect of SSBs. The effects of changes in food consumption to other food groups (eg, proteins, fat) are not modelled. Detrimental effects of these food categories are less well documented and inferior to the effects of added sugars. 
NHANES data were used to reduce individual added sugars consumption by the specified amount. From these data, new distributions were calculated to reflect subgroup consumption patterns. These distributions determined the ratio between individuals in the high-risk and the low-risk group and therefore determine progression within disease chains. Identical random numbers were used between interventions to reduce variance, as described by Stout and Goldie. ${ }^{73}$

\section{Time horizon, cycle length}

The model had a time horizon of 20 years, modelling the calendar years 2015-2035. This duration was chosen to make sure effects within chronic diseases (T2D, CHD) were sufficiently visible. The cycle length was 1 year. Individuals could exit the model through each death state or live until the end of the simulation.

\section{Outcomes}

Outcomes were incidence, prevalence and mortality of disease and direct medical costs and DALYs averted. Costs were calculated by multiplying prevalence by discounted disease-attributable costs. DALYs were calculated by adding years lived with disability (YLD) and years of life lost (YLL). YLD was calculated as the product of the prevalence of disease times the discounted disability weight. YLL was calculated by multiplying the discounted health-adjusted life expectancy at death by the amount of people that died in that specific year, given a certain age and sex. The discount rate for costs, disability weights and life expectancy was $3.0 \%$ annually. Health-adjusted life expectancy and discounted life expectancy for males and females for the USA were not derived by the model but implemented directly from publications of the Institute for Health Metrics and Evaluation (IHME). They are provided in the online supplementary tables 3 and 4 .

\section{Input parameter determination}

The model parameters that determined demographics and the distribution of risk factors and disease at the start of the simulation are mainly derived from the National Health Interview Survey (NHIS) and NHANES data. If data were not sufficient, current literature was consulted. Model input parameters, their distribution ranges and the sources from which they were acquired are presented in tables 1 and 2. Baseline transition probabilities were derived from literature data and, where necessary, via calibration. Also when necessary, we used logistic conversion to adjust transition rates to reflect annual probabilities. Interaction values were derived from literature data. For interactions between chains, we used conservative data when possible, to ensure no overestimation of effect size. We took special care to ensure these ORs reflect the case for our model, that is, reflect decreased risk due to a reduction in overall added sugars intake, not just a reduction in SSB intake, which is more commonly investigated. Regression rates were determined by historic and projected trends reported by the Centers for Disease Control and Prevention (CDC) and AHA. ${ }^{356}$ Costs were derived from American population-based studies and, where necessary, were inflated by the inflation calculator of the US Department of Labor Statistics to 2015 US $\$ .^{74}$ Costs were calculated as specific disease-attributable costs (ie, costs for CHD due to diabetes were counted as costs due to CHD rather than costs due to diabetes). This was necessary to prevent overlapping costs. Disability weights were adopted from WHO's burden of disease estimates and current literature. Specific sources are provided in the tables.

\section{Calibration}

Incidence, prevalence, mortality and costs of overweight and obesity, T2D and CHD were calibrated to reflect historic data from the CDC and projections from AHA and several individual studies predicting future disease. ${ }^{6} 7$ 75-79 NASH-related and cirrhosis-related HCC incidence and mortality was calibrated to historic trends reported by CDC and future predictions reported by the American Cancer Association. ${ }^{60}$

\section{Validation}

Validation of the model occurred via face validation, cross-validation and sensitivity analyses. Face validation was performed manually by the authors. Each chain was checked separately for functionality before merging them. Cross-validation was performed by comparing epidemiological outcomes and predictions from our model with reported results from different studies on each subject, as presented in the Discussion section.

Uncertainty was assessed using deterministic sensitivity analysis (DSA) and probabilistic sensitivity analysis (PSA). DSA was conducted using a 5-point analysis, with the minima and maxima specified in tables 1 and 2. If a mean and $\mathrm{SD}$ are specified, we used a range of mean $\pm 1.96 \times \mathrm{SD}$. DSA results are only presented for the two main outcomes: total costs and DALYs averted in the year 2035. PSA was conducted using the distributions defined in tables 1 and 2 , to produce a mean and $95 \%$ central coverage interval for all outcome values by running the simulation 10000 times (each of which including the base case and two interventions).

\section{Cohort simulation}

To produce stable results, limit computational requirements and have a cohort that remained representative of the US population, we simulated a base cohort of 22400 people, with new entry of 416 people each year, reflecting CDC population prospects. ${ }^{69}$ Because of computational requirements, the model was built in Golang programming language (Google, Mountain View, California, USA). Model code is publicly available via https:// github.com/alexgoodell/go-mdism or can be acquired through the corresponding author. Sensitivity analyses were conducted using a 20-machine cluster (Amazon Web Services, Seattle, Washington, USA). Outcome analysis was completed in Excel 2010 (Microsoft, Redmond, Washington, USA). 
Table 3 Annual occurring and averted events in 2035

\begin{tabular}{llllll}
\hline Per $\mathbf{1 0 0 0 0 0}$ people & & & \\
\hline Events & No intervention (CI) & 20\% reduction (Cl) & Difference (Cl) & $\mathbf{5 0 \% ~ r e d u c t i o n ~ ( C I ) ~}$ & Difference (CI) \\
\hline T2D cases & $1034.6(1031.0-1038.2)$ & $1014.7(1011.3-1018.2)$ & $19.9(12.8-27.0)$ & $951.2(947.9-954.4)$ & $83.5(76.7-90.3)$ \\
T2D deaths & $576.6(574.2-578.9)$ & $569.3(567.0-571.6)$ & $7.2(2.7-11.8)$ & $546.4(544.2-548.6)$ & $30.2(25.7-34.6)$ \\
CHD cases & $665.1(661.9-668.2)$ & $655.6(652.5-658.8)$ & $9.4(3.1-15.8)$ & $626.1(623.1-629.1)$ & $39.0(32.8-45.2)$ \\
CHD deaths & $203.6(202.2-205.0)$ & $201.9(200.5-203.3)$ & $1.6(-1.2-4.4)$ & $197.2(195.9-198.6)$ & $6.3(3.6-9.1)$ \\
HCC cases & $4.4(4.32-4.41)$ & $4.0(3.95-4.05)$ & $0.3(0.24-0.39)$ & $3.1(3.02-3.18)$ & $1.3(1.24-1.38)$ \\
Liver deaths & $19.8(19.65-20.02)$ & $18.5(18.29-18.63)$ & $1.4(1.02-1.73)$ & $14.1(13.94-14.21)$ & $5.8(5.44-6.08)$ \\
\hline
\end{tabular}

CHD, coronary heart disease; Cl, 95\% central coverage interval; HCC, hepatocellular carcinoma; NASH, non-alcoholic steatohepatitis; T2D, type 2 diabetes.

Numbers might not add up due to rounding.

\section{RESULTS}

\section{Incidence and mortality}

The incidence of T2D, CHD and HCC and the corresponding death rates in the year 2035 are stated in table 3. Diabetes incidence is expected to rise over the next 20 years, resulting in an incidence rate of 1035 cases per 100000 people. The interventions are expected to reduce this by 19.9 and 83.5 , respectively. CHD incidence is expected to rise to 665 cases per 100000 people by 2035 . This can be reduced by 9.4 and 39 cases by the $20 \%$ and the $50 \%$ intervention, respectively. NASH-related or cirrhosis-related HCC incidence will rise to 4.4 cases per 100000 people. Interventions could reduce this amount by 0.3 and 1.3 , respectively. Liver death can be due to HCC, or it can be related to NASH or cirrhosis in the absence of HCC. Liver-related deaths will rise substantially, to 19.8 deaths per 100000 people by 2035 . This can be reduced by 1.4 or 5.8 deaths per 100000 people by the $20 \%$ and $50 \%$ intervention, respectively.

\section{Prevalence}

Figure 2 graphs A-H show the reduction in prevalence of disease due to the two intervention strategies. A $20 \%$ reduction in added sugars consumption is expected to decrease prevalence of each disease state significantly after 20 years, except for overweight prevalence, which does not change significantly. A 50\% reduction in added sugars consumption will proportionally affect prevalence. Effects on T2D and CHD prevalences start to accumulate after an initial 3-year lag period. Graph $G$ shows that overweight prevalence is not reduced. This is because the individuals that regressed from obese to overweight offset the reduction achieved in people that started overweight and regressed to normal weight. This effect is clarified by the drop in obesity prevalence.

\section{Costs and DALYs}

An overview of economic findings is presented in table 4 . Overall costs for the modelled disease states could be reduced by $2.26 \%$ (95\% CI $2.23 \%$ to $2.29 \%$ ) by the year 2035 with an intervention that reduces added sugars intake by $20 \%$. The $50 \%$ intervention will reduce overall costs by $6.99 \%$ (95\% CI 6.91 to 7.08). DALY burden and averted DALYs are presented in table 5. Total amount of DALYs could be reduced by $4.32 \%$ (95\% CI $4.27 \%$ to $4.38 \%$ ) or $13.37 \%$ (95\% CI $13.24 \%$ to $13.51 \%$ ), respectively. The majority of averted DALYs are due to reduced mortality.
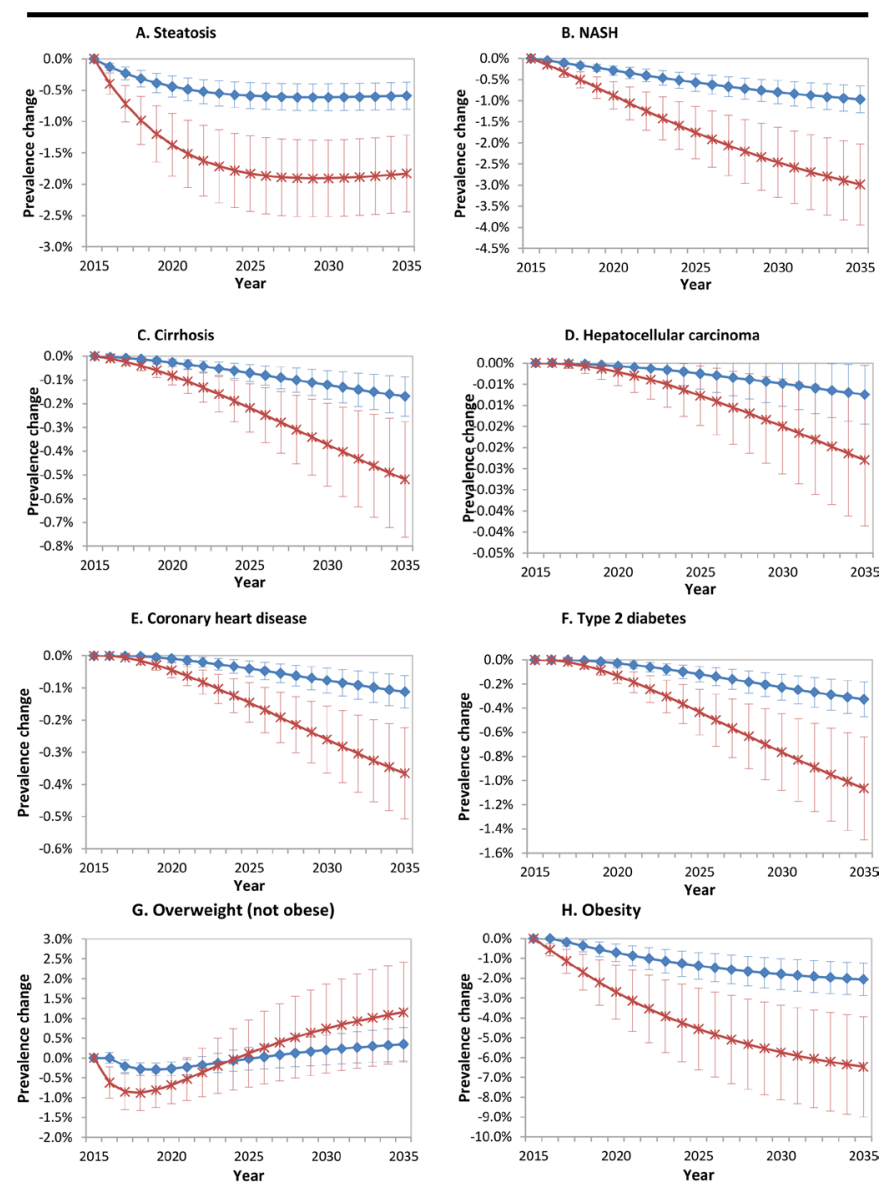

Figure 2. Graphs A-H. Reduction in population prevalence of disease due to interventions. Lines represent mean values $\pm 1 \mathrm{SD} ; 0 \%$ is the baseline, representing no intervention. The blue lines with diamonds indicate a reduction of added sugar of $20 \%$. The red lines with crosses represent a reduction of $50 \%$. NASH; non-alcoholic steatohepatitis. 
Table 4 Annual costs spent and averted per disease state in 2035

In billions 2015 US\$, discounted by $3.0 \%$ annually

\begin{tabular}{llllll}
\hline State & No intervention $\mathbf{( C l )}$ & $\mathbf{2 0 \%}$ reduction $\mathbf{( C l )}$ & Difference $(\mathbf{C l})$ & 50\% reduction $(\mathbf{C l})$ & Difference $(\mathbf{C l})$ \\
\hline Steatosis & $6.48(6.43-6.53)$ & $6.40(6.35-6.45)$ & $0.08(0.080-0.082)$ & $6.23(6.18-6.28)$ & $0.25(0.248-0.255)$ \\
NASH & $5.26(5.22-5.30)$ & $4.89(4.85-4.93)$ & $0.37(0.368-0.375)$ & $4.11(4.08-4.14)$ & $1.15(1.139-1.162)$ \\
Cirrhosis & $7.00(6.93-7.07)$ & $6.22(6.16-6.28)$ & $0.78(0.772-0.791)$ & $4.60(4.56-4.65)$ & $2.40(2.371-2.429)$ \\
HCC & $5.10(5.04-5.16)$ & $4.55(4.50-4.60)$ & $0.55(0.537-0.558)$ & $3.40(3.36-3.44)$ & $1.70(1.669-1.721)$ \\
CHD & $162.2(160.9-163.6)$ & $160.1(158.8-161.5)$ & $2.09(2.06-2.12)$ & $155.7(154.4-157.0)$ & $6.51(6.43-6.58)$ \\
T2D & $200.0(198.4-201.6)$ & $195.9(194.3-197.5)$ & $4.07(4.02-4.12)$ & $187.4(185.9-188.9)$ & $12.59(12.46-12.73)$ \\
Overweight & $16.4(16.3-16.5)$ & $16.6(16.5-16.8)$ & $-0.25(-0.26--0.25)$ & $17.2(17.1-17.3)$ & $-0.79(-0.81--0.78)$ \\
Obesity & $52.7(52.3-53.1)$ & $50.1(49.7-50.5)$ & $2.59(2.57-2.62)$ & $44.7(44.3-45.0)$ & $8.03(7.95-8.12)$ \\
Total & $455.1(451.4-458.9)$ & $444.9(441.2-448.5)$ & $10.3(10.2-10.4)$ & $423.3(419.8-426.8)$ & $31.8(31.5-32.2)$ \\
\hline
\end{tabular}

$\mathrm{CHD}$, coronary heart disease; $\mathrm{Cl}, 95 \%$ central coverage interval; HCC, hepatocellular carcinoma; NASH, non-alcoholic steatohepatitis; T2D, type 2 diabetes.

Numbers might not add up due to rounding.

\section{Sensitivity analyses}

We show tornado diagrams for the two most important outcomes: annual costs and DALYs averted by the year 2035 due to an intervention that reduces sugar consumption by $20 \%$. The diagrams show the impact that specific input parameters had on selected results. The 10 variables that caused the widest range in results are shown. When varying individual variables, the annual savings by the year 2035 range from 2015 US $\$ 7.9$ to US $\$ 17.1$ billion. The tornado diagram (figure 3) shows that the interaction between high added sugars consumption and the progression within the NAFLD and BMI chains had the greatest impact on total costs averted. In the tornado diagram for total annual DALYs averted by the $20 \%$ intervention in the year 2035 (figure 4), assigned disability weights had the greatest impact. Total DALYs averted ranged between 0.36 and 1.41 million.

\section{DISCUSSION}

It has been estimated that the cost burden of the diseases of metabolic syndrome is $75 \%$ of the total annual healthcare budget (US\$3.2 trillion) of the USA. The clinical burden of NAFLD alone is estimated at US $\$ 103$ billion. ${ }^{81}$ The proposed model shows clear and significant benefits for interventions that reduce consumption of added sugars. A reduction by $20 \%$ will reduce annual direct medical costs for US adults by more than US $\$ 10$ billion (2015 dollars) by the year 2035 . A 50\% reduction will save an additional 21 billion. Together with these economic benefits, population health will significantly improve. A total of 770000 DALYs could be averted with a $20 \%$ reduction in consumption. A $50 \%$ reduction in consumption will avert another 1.6 million DALYs. These health and economic benefits are the direct result of lower incidence, prevalence and mortality of disease in US adults due to lower consumption of added sugars. Averted costs

\begin{tabular}{|c|c|c|c|c|c|}
\hline \multicolumn{6}{|l|}{ In millions } \\
\hline State & No intervention (Cl) & $20 \%$ reduction $(\mathrm{Cl})$ & Difference (Cl) & $50 \%$ reduction $(\mathrm{Cl})$ & Difference (CI) \\
\hline NASH & 2.97 (2.955-2.988) & $2.76(2.746-2.777)$ & $0.210(0.209-0.212)$ & 2.32 (2.309-2.334) & $0.650(0.645-0.655)$ \\
\hline Cirrhosis & $0.48(0.475-0.482)$ & $0.42(0.422-0.428)$ & $0.053(0.053-0.054)$ & $0.31(0.312-0.316)$ & $0.164(0.162-0.165)$ \\
\hline $\mathrm{HCC}$ & $3.06(3.046-3.084)$ & 2.78 (2.765-2.799) & $0.283(0.279-0.283)$ & $2.19(2.180-2.206)$ & $0.872(0.863-0.881)$ \\
\hline CHD & $2.32(2.305-2.330)$ & $2.29(2.276-2.302)$ & $0.028(0.028-0.029)$ & $2.23(2.217-2.242)$ & $0.088(0.086-0.090)$ \\
\hline T2D & $8.21(8.180-8.248)$ & $8.06(8.023-8.089)$ & $0.158(0.155-0.160)$ & $7.72(7.690-7.752)$ & $0.492(0.487-0.498)$ \\
\hline Obesity & 0.69 (0.689-0.700) & $0.66(0.655-0.666)$ & $0.034(0.034-0.035)$ & $0.59(0.584-0.593)$ & $0.106(0.105-0.107)$ \\
\hline Total & $17.74(17.65-17.83)$ & $16.97(16.89-17.06)$ & $0.767(0.757-0.777)$ & $15.37(15.29-15.44)$ & $2.372(2.348-2.396)$ \\
\hline From mortality & 11.94 & 11.50 & 0.439 & 10.58 & 1.357 \\
\hline From morbidity & 5.80 & 5.47 & 0.328 & 4.78 & 1.015 \\
\hline
\end{tabular}

CHD, coronary heart disease; Cl, 95\% central coverage interval; DALY, disability-adjusted life year; HCC, hepatocellular carcinoma; NASH, non-alcoholic steatohepatitis; T2D, type 2 diabetes.

Numbers might not add up due to rounding. 
OR high sugar cons. for BMI TPS OR high sugar cons. for NAFLD TPS High sugar cons. \% NHW FEMALE Annual direct costs for obesity OR NAFLD for TP Healthy -> CHD Annual direct costs for $\mathrm{CHD}$ Annual direct costs for T2D High sugar cons. \% NHW MALE Annual direct costs for cirrhosis Annual direct costs for NASH

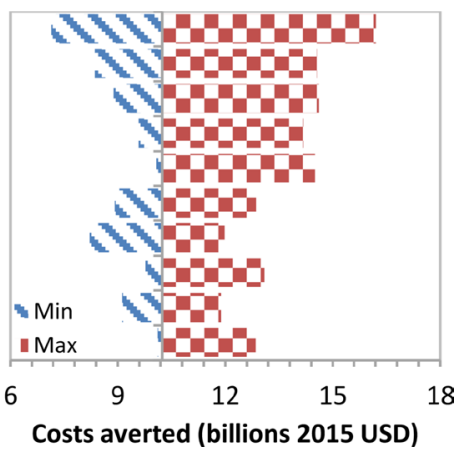

Figure 3 Tornado diagram of the 10 most critical variables on total costs averted in the year 2035. BMI, body mass index; CHD, coronary heart disease; NAFLD, non-alcoholic fatty liver disease; T2D, type 2 diabetes; TP, transition probability; NHW, Non-Hispanic White.

are achieved primarily through reduced costs for CHD, T2D, overweight and obesity. This is mainly because costs for the most prevalent NAFLD states, namely, steatosis and NASH, are fairly low, whereas costs for other illnesses are much higher (table 1). In averted DALYs, we find that the combination of disability weight and prevalence changes are predictors of DALY reductions. For example, NASH has a lower disability weight but higher prevalence reductions, and therefore, we find almost equal DALY reductions compared with $\mathrm{HCC}$ or CHD. T2D has the highest reduction in DALY burden because it has relatively large values for both prevalence reduction and disability weight.

\section{Fit with current knowledge}

The estimate for health and economic benefit of this model is similar to a number of previously performed economic evaluations. Basu et al found a reduction in diabetes incidence of 21.7 cases per 100000 people with a reduction of $20 \%$ of added sugars through a cap-andtrade approach, limiting the amount of sugars in the food supply. ${ }^{65}$ We found a reduction of 19.9 cases per 100000 people, indicating a similar absolute effect size. CHD incidence reduction is estimated to be about 1.5-fold higher than found in a similar study, but we argue that this is

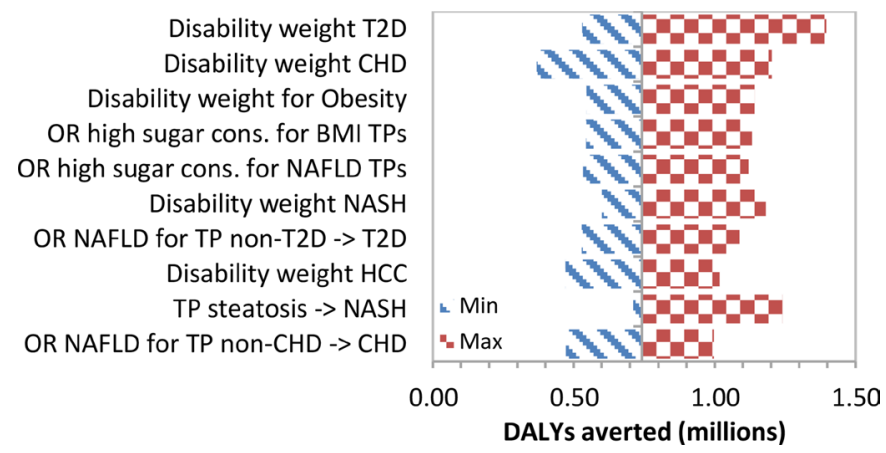

Figure 4 Tornado diagram of the ten most critical variables on total DALYs averted in the year 2035. BMI, body mass index; CHD, coronary heart disease; DALY, disability-adjusted life year; NAFLD, non-alcoholic fatty liver disease; T2D, type 2 diabetes; TP, transition probability. mainly because the other study simulated a $20 \%$ tax on SSBs, and therefore the overall added sugars consumption reduction was smaller than the $20 \%$ reduction we simulated. ${ }^{63}$ In an econometric analysis looking backward in time, Basu et alfound a delay of 3 years between changes in sugar consumption and prevalence of diabetes. ${ }^{37}$ Similarly, we found a delay of 3 years going forward in time between reduction of consumption and reduction in prevalence of disease. Prevalence of obesity has been reported to drop by $1.5 \%-10 \%$ due to a reduction of added sugars by $10 \%-20 \% .^{59-61}$ Our result of $2.1 \%$ reduction in obesity prevalence seems to reflect our conservative approach in determining input parameter values.

Costs savings are bigger in our model compared with other models. ${ }^{606464}$ This was for three reasons. First, some other models do not use added sugars as a whole but use SSBs, resulting in a smaller effect. Second, our overall prevalence of T2D and CHD is higher than most other models. We have calibrated our model to historic trends reported by CDC and to future projections of the AHA, the American Diabetes Association (ADA) and separate studies predicting future prevalence and therefore argue that our estimate is valid. Third, and perhaps most importantly, no other studies predict future NAFLD prevalence. We present the first model that estimates the effects of sugar interventions on NAFLD prevalence and associated costs and DALYs.

In 2009, the AHA recommended a reduction in added sugar consumption from a median of $90 \mathrm{~g}$ per day to a maximum of $25 \mathrm{~g}$ for women and $37.5 \mathrm{~g}$ for men. ${ }^{31}$ In 2016, USDA and WHO settled on an upper limit of $10 \%$ of calories, which approximates $50 \mathrm{~g}$ per day. Given the US current median consumption of $80 \mathrm{~g}$ per day, our microsimulation modelling cutoffs of $20 \%$ and $50 \%$, while ambitious, are metabolically rational and in concert with governmental goals. ${ }^{82}$

Our model only allows us to examine the negative side of the balance sheet in terms of cost savings to healthcare. However, reductions in added sugar consumption have been modelled to provide significant increases to the positive side of the balance sheet in terms of economic productivity. Indeed, a simulation modelling by Morgan Stanley predicted economic growth to decline to zero by the year 2035 using a high-sugar case, whereas stabilisation at $+2.9 \%$ was noted with a low-sugar case. ${ }^{83}$

\section{Strengths and limitations}

This study is the first of its kind to model the effect of added sugars on NAFLD as well as on BMI, and therefore it captures a more complete picture of the possible health and economic benefits of interventions that reduce intake of added sugars. Though taxing sugar-sweetened products, mainly beverages, has been widely suggested as a public health strategy, other approaches (eg, a cap-andtrade approach) have also been suggested. ${ }^{58-61}$ 63-65 We have constructed this model to be applicable with each of these interventions, so that it does not rely on any consumption statistics other than added sugars as a 
whole. A limitation to this approach is that our model does not incorporate a possible change to non-sugared caloric products, containing protein, fat or other carbohydrates. While it is conceivable that removal of added sugars in the diet could result in subsequent substitution of other foodstuffs to restore an individual's caloric baseline, ad lib population studies do not support that such caloric compensation takes place. ${ }^{84}$ It is important that effort is put into investigating self-elasticity and cross-elasticity of sugar-sweetened products to determine the effect of these caloric replacements. Though this is a limitation, research has clearly shown that the contribution of added sugars in relation to their excessive intake is likely the most important consumption factor for metabolic derangement. Furthermore, added sugars consumption was fixed throughout the simulation for each individual (though specified per sex and ethnic group). We could not find sufficient data on changes in sugar consumption related to incident disease and therefore could not model these changes accurately enough. We argue that keeping the sugar consumption fixed is likely more accurate than modelling changing sugar consumption based solely on age. The main limitation of this model is the uncertainty of input parameters. The pathophysiology of NAFLD and its associations with other metabolic diseases is still widely under investigation. We have modelled cirrhosis as an irreversible condition, which is not necessarily true in all cases. Furthermore, the input parameters for baseline transition probabilities and interaction (OR) values are still somewhat uncertain. Many studies report associations, but very few studies report plausible quantitative causal relationships. There are several reasons that explain this low number of studies. First, it is hard to accurately determine the individual components in an individual's diet. Second, there is no inexpensive, accurate way to determine the presence of individual NAFLD states. Commonly used ultrasonography possibly underestimates the prevalence of NAFLD and does not differentiate between steatosis and NASH, while up to $79 \%$ of patients may have serum alanine aminotransferase levels within the normal reference range of $<40 \mathrm{U} /$ mL. ${ }^{9} 85$ Additionally, the studies that we included to define our input parameters are generally not a perfect reflection of the population that we modelled, which may lead to imperfect estimates of values. We have addressed these uncertainties in inputs by taking wide ranges in the probabilistic sensitivity analysis, which determines the SD and $95 \%$ central coverage interval around the results. Results remain statistically significant, indicating that any minor inaccuracies in input parameter values will not render the effects insignificant. Ultimately, it is desirable to determine incidence of NAFLD states and risk factor relative risks in independent prospective cohort studies and to assess intervention effectiveness via randomised controlled trials. This model can be refined and updated when new data become available.

It is possible that our results might still underestimate the total effects. We only modelled diagnosed disease, we took a conservative approach when determining input parameter values and we did not take societal costs into account. Real health, healthcare and economic benefits are likely larger than estimated. Furthermore, we only modelled the population with an age over 20. Likely, including health effects in children, particularly those with T2D, would yield additional benefits.

\section{Implications}

This model clarifies the significant health and economic benefits that could be achieved by a public health intervention that reduces consumption of added sugars in US adults. We recommend that health policy makers review options to implement sugar reduction. Important to consider are the barriers to limiting added sugars in the USA. The food industry uses sugar to enhance flavour and as a bulking and browning agent, humectant and spoilage retardant. Another obstacle is the lowered price for manufacturing, due to government subsidies for corn, cane and beets. Historically, there was another barrierlack of consensus on the link between sugar and metabolic disease. However, consensus on causality is now strong. ${ }^{86}$ Recently sugar taxation has emerged as a viable strategy, levied in the UK and Mexico, as well as several municipalities in the USA, including San Francisco, Oakland, Berkeley and Albany, California, as well as Chicago, Illinois, and Philadelphia, Pennsylvania.

\section{Future research}

Future research should focus on establishing a more precise measurement of NAFLD prevalence, incidence and risk factors. Furthermore, magnitude and effects of switching to different food groups should be assessed. Finally, changes in added sugars consumption related to ageing and incident disease should be more intensively investigated.

Contributors RAV was involved in conceptualising the study, reviewing literature, conducting the modelling analysis, analysing the data and writing the manuscript. AJG was involved in conducting the modelling analysis and in editing the paper. LAR and RHL were involved in conceptualising the model, providing and structuring data inputs and editing the manuscript. TCP was involved in reviewing and revising the manuscript, checking statistical and mathematical assumptions and establishing overall validity of the model. JGK was involved in conceptualisation of the model, input data review, guiding the modelling process and providing a critical review of the manuscript. All authors read and approved the final manuscript.

Competing interests RHL has received author fees from Hudson Street Press regarding his authorship of 'Fat Chance: Beating the Odds Against Sugar, Processed Food, Obesity, and Disease', 'The Fat Chance Cookbook' and 'Sugar has 56 names: A Shopper's Guide'. He is also the unpaid chief science officer of the non-profit EatREAL.

Provenance and peer review Not commissioned; externally peer reviewed.

Data sharing statement An online supplement will be made available containing comprehensive tables of used input data. The modelling code is available through github (https://github.com/alexgoodell/go-mdism) or can be accessed via the corresponding author.

Open Access This is an Open Access article distributed in accordance with the Creative Commons Attribution Non Commercial (CC BY-NC 4.0) license, which permits others to distribute, remix, adapt, build upon this work non-commercially, and license their derivative works on different terms, provided the original work is properly cited and the use is non-commercial. See: http://creativecommons.org/ licenses/by-nc/4.0/ 
(c) Article author(s) (or their employer(s) unless otherwise stated in the text of the article) 2017. All rights reserved. No commercial use is permitted unless otherwise expressly granted.

\section{REFERENCES}

1. Flegal KM, Kruszon-Moran D, Carroll MD, et al. Trends in obesity among adults in the United States, 2005 to 2014. JAMA 2016;315:2284-91.

2. Centers for Disease Control and Prevention. National Center for Health Statistics. Health Data Interactive 2015 www.cdc.gov/nchs/ hdi.htm

3. Centers for Disease Control and Prevention. National Center for Health Statistics. National Health and Nutrition Examination Survey Data. Hyattsville, MD: U.S. Department of Health and Human Services, Centers for Disease Control and Prevention. 2005-2012. http://www.cdc.gov/nchs/nhanes.htm

4. American Heart Association. Heart Disease and Stroke Statistics-2005 Update: Dallas, Texas: American Heart Association, 2005.

5. Mozaffarian D, Benjamin EJ, Go AS, As G, et al. Heart disease and stroke statistics - 2015 update: a report from the American Heart Association. Circulation 2015;131:e29-322.

6. Centers for Disease Control and Prevention. Data are from the Multiple Cause of Death Files, 1999-2013, as compiled from data provided by the 57 vital statistics jurisdictions through the Vital Statistics Cooperative Program: National Center for Health Statistics. Underlying Cause of Death 1999-2013 on CDC WONDER Online Database, released 2015, 2015. http://wonder cdc.gov/ucd-icd10.html

7. Heidenreich PA, Trogdon JG, Khavjou OA, et al. Forecasting the future of cardiovascular disease in the United States: a policy statement from the American Heart Association. Circulation 2011;123:933-44.

8. American Diabetes Association. Economic costs of diabetes in the U.S. Diabetes Care 2008;615:596:31.

9. Browning JD, Szczepaniak LS, Dobbins R, et al. Prevalence of hepatic steatosis in an urban population in the United States: impact of ethnicity. Hepatology 2004;40:1387-95.

10. Yki-Järvinen $\mathrm{H}$. Non-alcoholic fatty liver disease as a cause and a consequence of metabolic syndrome. Lancet Diabetes Endocrinol 2014;2:901-10.

11. Lonardo A, Ballestri S, Marchesini G, et al. Nonalcoholic fatty liver disease: a precursor of the metabolic syndrome. Dig Liver Dis 2015;47:181-90.

12. Ballestri S, Nascimbeni F, Romagnoli D, et al. The independent predictors of non-alcoholic steatohepatitis and its individual histological features: insulin resistance, serum uric acid, metabolic syndrome, alanine aminotransferase and serum total cholesterol are a clue to pathogenesis and candidate targets for treatment. Hepatol Res Off J Jpn Soc Hepatol 2016;46:1074-87.

13. Chalasani N, Younossi Z, Lavine JE, et al. The diagnosis and management of non-alcoholic fatty liver disease: practice guideline by the American Gastroenterological Association, American Association for the study of liver diseases, and American College of Gastroenterology. Gastroenterology 2012;142:1592-609.

14. Tiniakos DG. Nonalcoholic fatty liver disease/nonalcoholic steatohepatitis: histological diagnostic criteria and scoring systems. Eur J Gastroenterol Hepatol 2010;22:643-50.

15. Farazi PA, DePinho RA. Hepatocellular carcinoma pathogenesis: from genes to environment. Nat Rev Cancer 2006;6:674-87.

16. Wree A, Broderick L, Canbay A et al. From NAFLD to NASH to cirrhosis - new insights into disease mechanisms. Nat Rev Gastroenterol Hepatol 2013;10:627-36.

17. Mahady SE, George J. Management of nonalcoholic steatohepatitis: an evidence-based approach. Clin Liver Dis 2012;16:631-45.

18. LaBrecque DR, Abbas Z, Anania F, et al. World Gastroenterology Organisation global guidelines: nonalcoholic fatty liver disease and nonalcoholic steatohepatitis. J Clin Gastroenterol 2014;48:467-73.

19. Williams CD, Stengel J, Asike MI, et al. Prevalence of nonalcoholic fatty liver disease and nonalcoholic steatohepatitis among a largely middle-aged population utilizing ultrasound and liver biopsy: a prospective study. Gastroenterology 2011;140:124-31.

20. Peery AF, Dellon ES, Lund J, et al. Burden of gastrointestinal disease in the United States: 2012 update. Gastroenterology 2012;143:e1:1179-87.

21. Gastaldelli A, Cusi K, Pettiti M, et al. Relationship between hepatic/ visceral fat and hepatic insulin resistance in nondiabetic and type 2 diabetic subjects. Gastroenterology 2007;133:496-506.
22. Dietrich P, Hellerbrand C. Non-alcoholic fatty liver disease, obesity and the metabolic syndrome. Best Pract Res Clin Gastroenterol 2014;28:637-53.

23. Fukuda T, Hamaguchi M, Kojima T, et al. The impact of nonalcoholic fatty liver disease on incident type 2 diabetes mellitus in non-overweight individuals. Liver Int 2016;36:275-83.

24. Sattar N, McConnachie A, Ford I, et al. Serial metabolic measurements and conversion to type 2 diabetes in the west of Scotland coronary prevention study: specific elevations in alanine aminotransferase and triglycerides suggest hepatic fat accumulation as a potential contributing factor. Diabetes 2007;56:984-91.

25. Thomas EL, Brynes AE, Hamilton G, et al. Effect of nutritional counselling on hepatic, muscle and adipose tissue fat content and distribution in non-alcoholic fatty liver disease. World $J$ Gastroenterol 2006;12:5813-9.

26. Vanni E, Bugianesi E, Kotronen A, et al. From the metabolic syndrome to NAFLD or vice versa? Digestive and Liver Disease 2010;42:320-30.

27. Larson-Meyer DE, Heilbronn LK, Redman LM, et al. Effect of calorie restriction with or without exercise on insulin sensitivity, beta-cell function, fat cell size, and ectopic lipid in overweight subjects. Diabetes Care 2006;29:1337-44.

28. Marriott BP, Cole N, Lee E. National estimates of dietary fructose intake increased from 1977 to 2004 in the United States. J Nutr 2009;139:1228S.

29. Wang DD, Leung CW, Li Y, et al. Trends in dietary quality among adults in the United States, 1999 through 2010. JAMA Intern Med 2014;174:1587-95.

30. Welsh JA, Sharma AJ, Grellinger L, et al. Consumption of added sugars is decreasing in the United States. Am J Clin Nutr 2011;94:726-34.

31. Johnson RK, Appel LJ, Brands M, et al. Dietary sugars intake and cardiovascular health: a scientific statement from the American Heart Association. Circulation 2009;120:1011-20.

32. U.S. Dept. of Agriculture. HHS and USDA release new dietary guidelines to encourage healthy eating patterns to prevent chronic diseases: USDA Press, Report 202-720-4623. https://www.fns. usda.gov/pressrelease/2016/000516.

33. EFSA Panel on Dietetic Products, Nutrition and Allergies (NDA). Scientific opinion on dietary reference values for carbohydrates and dietary fibre. Efsa J 2010;8:1462.

34. Vos MB, Kaar JL, Welsh JA, et al. Added sugars and cardiovascular disease risk in children: a scientific statement from the American Heart Association. Circulation 2017;135:e1017-34.

35. Rodríguez LA, Madsen KA, Cotterman C, et al. Added sugar intake and metabolic syndrome in US adolescents: cross-sectional analysis of the National Health and Nutrition Examination Survey 2005-2012. Public Health Nutr 2016;19:2424-34.

36. Yang Q, Zhang Z, Gregg EW, et al. Added sugar intake and cardiovascular diseases mortality among US adults. JAMA Intern Med 2014:174:516-24.

37. Basu S, Yoffe P, Hills N, et al. The relationship of sugar to population-level diabetes prevalence: an econometric analysis of repeated cross-sectional data. PLoS One 2013;8:e57873.

38. Abid A, Taha O, Nseir W, et al. Soft drink consumption is associated with fatty liver disease independent of metabolic syndrome. $J$ Hepatol 2009;51:918-24.

39. Lustig RH. Fructose: It's "Alcohol without the buzz.". Advances in Nutrition: An International Review Journal 2013;4:226-35.

40. Lustig $\mathrm{RH}$, Mulligan $\mathrm{K}$, Noworolski SM, et al. Isocaloric fructose restriction and metabolic improvement in children with obesity and metabolic syndrome. Obesity 2016;24:453-60.

41. Schwarz JM, Noworolski SM, Wen MJ, et al. Effect of a highfructose weight-maintaining diet on lipogenesis and liver fat. J Clin Endocrinol Metab 2015;100:2434-42.

42. Imamura F, O'Connor L, Ye Z, et al. Consumption of sugar sweetened beverages, artificially sweetened beverages, and fruit juice and incidence of type 2 diabetes: systematic review, metaanalysis, and estimation of population attributable fraction. BMJ 2015;351:h3576.

43. Bray GA, Popkin BM. Dietary sugar and body weight: have we reached a crisis in the epidemic of obesity and diabetes? Health be damned! Pour on the sugar. Diabetes Care 2014;37:950-6.

44. Lim JS, Mietus-Snyder M, Valente A, et al. The role of fructose in the pathogenesis of NAFLD and the metabolic syndrome. Nat Rev Gastroenterol Hepatol 2010;7:251-64.

45. Maersk M, Belza A, Stødkilde-Jørgensen H, et al. Sucrosesweetened beverages increase fat storage in the liver, muscle, and visceral fat depot: a 6-mo randomized intervention study. Am J Clin Nutr 2012;95:283-9. 
46. Stanhope KL, Schwarz JM, Keim NL, et al. Consuming fructosesweetened, not glucose-sweetened, beverages increases visceral adiposity and lipids and decreases insulin sensitivity in overweight/ obese humans. J Clin Invest 2009;119:1322-34.

47. Pollock NK, Bundy V, Kanto W, et al. Greater fructose consumption is associated with cardiometabolic risk markers and visceral adiposity in adolescents. J Nutr 2012;142:251-7.

48. Sevastianova K, Santos A, Kotronen A, et al. Effect of short-term carbohydrate overfeeding and long-term weight loss on liver fat in overweight humans. Am J Clin Nutr 2012;96:727-34.

49. Nguyen S, Choi HK, Lustig RH, et al. Sugar-sweetened beverages, serum uric acid, and blood pressure in adolescents. $J$ Pediatr 2009;154:807-13.

50. Chen L, Caballero B, Mitchell DC, et al. Reducing consumption of sugar-sweetened beverages is associated with reduced blood pressure: a prospective study among United States adults. Circulation 2010;121:2398-406.

51. Romaguera D, Norat T, Wark PA, et al. Consumption of sweet beverages and type 2 diabetes incidence in european adults: results from EPIC-InterAct. Diabetologia 2013;56:1520-30.

52. Ballestri S, Zona S, Targher G, et al. Nonalcoholic fatty liver disease is associated with an almost twofold increased risk of incident type 2 diabetes and metabolic syndrome. evidence from a systematic review and meta-analysis. J Gastroenterol Hepatol 2016;31:936-44.

53. Gugliucci A, Lustig RH, Caccavello R, et al. Short-term isocaloric fructose restriction lowers apoC-III levels and yields less atherogenic lipoprotein profiles in children with obesity and metabolic syndrome. Atherosclerosis 2016;253:171-7.

54. Schwarz JM, Noworolski SM, Erkin-Cakmak A, Gugliucci $\mathrm{A}$, et al. Effects of dietary fructose restriction on liver fat, de novo lipogenesis, and insulin kinetics in children with obesity. Gastroenterology. In Press. 2017.

55. Perry RJ, Samuel VT, Petersen KF, et al. The role of hepatic lipids in hepatic insulin resistance and type 2 diabetes. Nature 2014;510:84-91.

56. Templeman NM, Skovs $ø$ S, Page MM, et al. A causal role for hyperinsulinemia in obesity. J Endocrinol 2017;232:R173-83.

57. Jia G, DeMarco VG, Sowers JR. Insulin resistance and hyperinsulinaemia in diabetic cardiomyopathy. Nat Rev Endocrinol 2016;12:144-53.

58. Brownell KD, Farley T, Willett WC, et al. The public health and economic benefits of taxing sugar-sweetened beverages. $N$ Engl $J$ Med 2009;361:1599-605.

59. Mytton OT, Eyles H, Ogilvie D. Evaluating the health impacts of food and beverage taxes. Curr Obes Rep 2014;3:432-9.

60. Wang YC, Coxson P, Shen YM, et al. A penny-per-ounce tax on sugar-sweetened beverages would cut health and cost burdens of diabetes. Health Aff 2012;31:199-207.

61. Smith TA, Lin B, Lee J. Taxing Caloric Sweetened Beverages: Potential Effects on Beverage Consumption, Calorie Intake, and Obesity, ERR-100, U.S. Department of Agriculture, Economic Research Service, 2010.

62. Colchero MA, Rivera-Dommarco J, Popkin BM, et al. In Mexico, evidence of sustained consumer response two years after implementing a sugar-sweetened beverage tax. Health Aff 2017;36:564-71.

63. Mekonnen TA, Odden MC, Coxson PG, et al. Health benefits of reducing sugar-sweetened beverage intake in high risk populations of California: results from the cardiovascular disease (CVD) policy model. PLoS One 2013;8:e81723.

64. Basu S, Seligman HK, Gardner C, et al. Ending SNAP subsidies for sugar-sweetened beverages could reduce obesity and type 2 diabetes. Health Aff 2014;33:1032-9.

65. Basu S, Lewis K. Reducing added sugars in the food supply through a cap-and-trade approach. Am J Public Health 2014;104:2432-8.

66. Caro JJ, Briggs AH, Siebert U, et al. Modeling good research practices-overview: a report of the ISPOR-SMDM Modeling Good Research Practices Task Force-1. Value in Health 2012;15:796-803.

67. Husereau D, Drummond M, Petrou S, et al. Consolidated Health Economic Evaluation Reporting Standards (CHEERS) - explanation and elaboration: a report of the ISPOR Health Economic Evaluation Publication Guidelines Good Reporting Practices Task Force. Value Health 2013;16:231-50.

68. Stewart WJ. Introduction to the numerical solution of Markov chains. 1st ed. Princeton University Press: Princeton, 1994.

69. U.S. Census Bureau, Population Division. Table 9: projections of the population by sex and age for the United States: 2015 to 2060 (NP2014-T9), 2014. http://www.census.gov/population/projections/

70. National Center for Health Statistics (U.S.).ed: National Health and Nutrition Examination Survey: Analytic Guidelines, 1999-2010.
Hyattsville, Maryland: U.S. Department of Health and Human Services, Centers for Disease Control and Prevention, National Center for Health Statistics, 2013.

71. United States Department of Agriculture. Food patterns equivalents database. USDA Agricultural Research Service. http://www.ars. usda.gov/Services/docs.htm?docid=23869 (accessed 29 Jan 2015).

72. Geiss LS, Wang J, Cheng YJ, et al. Prevalence and incidence trends for diagnosed diabetes among adults aged 20 to 79 years, United States, 1980-2012. JAMA 2014;312:1218-26.

73. Stout NK, Goldie SJ. Keeping the noise down: common random numbers for disease simulation modeling. Health Care Manag Sci 2008;11:399-406.

74. United States Department of Labor. CPI Inflation Calculator. http:// www.bls.gov/data/inflation_calculator.htm

75. Gregg EW, Boyle JP, Thompson TJ, et al. Modeling the impact of prevention policies on future diabetes prevalence in the United States: 2010-2030. Popul Health Metr 2013;11:18.

76. Guariguata L, Whiting DR, Hambleton I, et al. Global estimates of diabetes prevalence for 2013 and projections for 2035. Diabetes Res Clin Pract 2014;103:137-49.

77. Huang ES, Basu A, O'Grady M, O'Grady M, et al. Projecting the future diabetes population size and related costs for the u.s. Diabetes Care 2009;32:2225-9.

78. Finkelstein EA, Khavjou OA, Thompson $\mathrm{H}$, et al. Obesity and severe obesity forecasts through 2030. Am J Prev Med 2012;42:563-70.

79. Odden MC, Coxson PG, Moran A, et al. The impact of the aging population on coronary heart disease in the United States. Am J Med 2011;124:827-33.

80. American Cancer Society. cer Facts \& Figures 2012. Atlanta: American Cancer Society, 2012.

81. Younossi ZM, Blissett D, Blissett R, et al. The economic and clinical burden of nonalcoholic fatty liver disease in the United States and Europe. Hepatology 2016;64:1577-86.

82. Ervin RB, Ogden CL. Consumption of added sugars among U.S. adults, 2005-2010. NCHS Data Brief 2013:1-8.

83. Morgan Stanley Research (2015). The bittersweet aftertaste of sugar. 2015. $18 \mathrm{http}: / /$ static.latribune.fr/463077/etude-morganstanley-impact-diabete-sur-I-economie-mondiale.pdf

84. Gombi-Vaca MF, Sichieri R, Verly-Jr E. Caloric compensation for sugar-sweetened beverages in meals: a population-based study in Brazil. Appetite 2016:98:67-73.

85. Saadeh S, Younossi ZM, Remer EM, et al. The utility of radiological imaging in nonalcoholic fatty liver disease. Gastroenterology 2002;123:745-50.

86. Lustig RH. Sickeningly sweet: does sugar cause type 2 diabetes? Yes. Can J Diabetes 2016;40:282-6.

87. Zhang E, Wartelle-Bladou C, Lepanto L, et al. Cost-utility analysis of nonalcoholic steatohepatitis screening. Eur Radiol 2015;25:3282-94.

88. Murray CJ, Vos T, Lozano R, et al. Disability-adjusted life years (DALYs) for 291 diseases and injuries in 21 regions, 1990-2010: a systematic analysis for the global burden of disease study 2010. Lancet 2012;380:2197-223.

89. Michelotti GA, Machado MV, Diehl AM. NAFLD, NASH and liver cancer. Nat Rev Gastroenterol Hepatol 2013;10:656-65.

90. Page JM, Harrison SA. NASH and HCC. Clin Liver Dis 2009:13:631-47.

91. Foster T, Anania FA, Li D, et al. The prevalence and clinical correlates of nonalcoholic fatty liver disease (NAFLD) in African Americans: the multiethnic study of atherosclerosis (MESA). Dig Dis Sci 2013;58:2392-8.

92. Farrell GC, Larter CZ. Nonalcoholic fatty liver disease: from steatosis to cirrhosis. Hepatol Baltim Md 2006;43:S99-112.

93. Baumeister SE, Völzke H, Marschall P, et al. Impact of fatty liver disease on health care utilization and costs in a general population: a 5-year observation. Gastroenterology 2008;134:85-94.

94. Adams LA, Lymp JF, St Sauver J, et al. The natural history of nonalcoholic fatty liver disease: a population-based cohort study. Gastroenterology 2005;129:113-21.

95. Ascha MS, Hanouneh IA, Lopez R, et al. The incidence and risk factors of hepatocellular carcinoma in patients with nonalcoholic steatohepatitis. Hepatology 2010;51:1972-8.

96. Bambha K, Belt P, Abraham M, et al. for the Nonalcoholic Steatohepatitis Clinical Research Network Research Group. Ethnicity and nonalcoholic fatty liver disease. Hepatology 2012:55:769-80.

97. McAdam-Marx C, McGarry LJ, Hane CA, et al. All-cause and incremental per patient per year cost associated with chronic hepatitis $C$ virus and associated liver complications in the United States: a managed care perspective. J Manag Care Pharm 2011;17:531-46. 46. 
98. Lightwood J, Bibbins-Domingo K, Coxson P, et al. Forecasting the future economic burden of current adolescent overweight: an estimate of the coronary heart disease policy model. Am J Public Health 2009;99:2230-7.

99. American Diabetes Association. Economic costs of diabetes in the U.S. in 2012. Diabetes Care 2013;36:1033-46.

100. Li Q, Blume SW, Huang JC, et al. The economic burden of obesity by glycemic stage in the United States. Pharmacoeconomics 2015;33:735-48.

101. Darbà J, Kaskens L, Detournay B, et al. Disability-adjusted life years lost due to diabetes in France, Italy, Germany, Spain, and the United Kingdom: a burden of illness study. Clinicoecon Outcomes Res 2015;7:163-71.

102. Keating CL, Peeters A, Swinburn BA, et al. Utility-based quality of life associated with overweight and obesity: the Australian diabetes, obesity, and lifestyle study. Obesity 2013;21:652-5.

103. U.S. Census Bureau, Population Division. Population Estimates, 2015. http://www.census.gov/popest/index.html.

104. Anstee QM, Targher G, Day CP. Progression of NAFLD to diabetes mellitus, cardiovascular disease or cirrhosis. Nat Rev Gastroenterol Hepatol 2013;10:330-44.

105. Bruno S, Maisonneuve P, Castellana P, et al. Incidence and risk factors for non-alcoholic steatohepatitis: prospective study of 5408 women enrolled in Italian tamoxifen chemoprevention trial. BMJ 2005;330:932.

106. Ekstedt M, Franzén LE, Mathiesen UL, et al. Long-term follow-up of patients with NAFLD and elevated liver enzymes. Hepatology 2006;44:865-73.

107. Haukeland JW, Lorgen I, Schreiner LT, et al. Incidence rates and causes of cirrhosis in a Norwegian population. Scand $J$ Gastroenterol 2007;42:1501-8.

108. Musso G, Cassader M, Bo S, et al. Sterol regulatory elementbinding factor 2 (SREBF-2) predicts 7-year NAFLD incidence and severity of liver disease and lipoprotein and glucose dysmetabolism. Diabetes 2013;62:1109-20.

109. Omagari K, Kadokawa $\mathrm{Y}$, Masuda J, et al. Fatty liver in nonalcoholic non-overweight japanese adults: incidence and clinical characteristics. J Gastroenterol Hepatol 2002;17:1098-105.

110. Rafiq N, Bai C, Fang Y, et al. Long-term follow-up of patients with nonalcoholic fatty liver. Clinical Gastroenterology and Hepatology 2009;7:234-8.

111. Wong VW, Wong GL, Yeung DK, et al. Incidence of non-alcoholic fatty liver disease in Hong Kong: a population study with paired proton-magnetic resonance spectroscopy. $J$ Hepatol 2015:62:182-9.

112. Zelber-Sagi S, Lotan R, Shlomai A, et al. Predictors for incidence and remission of NAFLD in the general population during a sevenyear prospective follow-up. J Hepatol 2012;56:1145-51.

113. Kawamura $Y$, Arase $Y$, Ikeda $K$, et al. Large-scale long-term followup study of Japanese patients with non-alcoholic fatty liver disease for the onset of hepatocellular carcinoma. Am J Gastroenterol 2012;107:253-61.

114. Njei B, Rotman $Y$, Ditah I, et al. Emerging trends in hepatocellular carcinoma incidence and mortality. Hepatology 2015;61:191-9.

115. El-Serag HB, Mason AC. Rising incidence of hepatocellular carcinoma in the United States. N Engl J Med 1999;340:745-50.

116. Lazo M, Hernaez R, Bonekamp S, et al. Non-alcoholic fatty liver disease and mortality among US adults: prospective cohort study. BMJ 2011;343:d6891.

117. Stepanova M, Rafiq N, Makhlouf $\mathrm{H}$, et al. Predictors of all-cause mortality and liver-related mortality in patients with non-alcoholic fatty liver disease (NAFLD). Dig Dis Sci 2013;58:3017-23.

118. Söderberg C, Stål $P$, Askling J, et al. Decreased survival of subjects with elevated liver function tests during a 28 -year follow-up. Hepatology 2010;51:595-602.

119. Haflidadottir S, Jonasson JG, Norland H, et al. Long-term followup and liver-related death rate in patients with non-alcoholic and alcoholic related fatty liver disease. BMC Gastroenterol 2014;14:166.

120. National Heart, Lung, and Blood Institute. Morbidity \& Mortality: 2012 Chart Book on Cardiovascular, Lung, and Blood Diseases. National Institutes of Health: National Heart, Lung, and Blood Institute, 2012

121. National Heart, Lung, and Blood Institute. Incidence and Prevalence: 2006 Chart Book on Cardiovascular and Lung Diseases: National Institutes of Health. National Heart, Lung, and Blood Institute, 2006.

122. Fishman El, Stokes A, Preston SH. The dynamics of diabetes among birth cohorts in the U.S. Diabetes Care 2014;37:1052-9.

123. Daouli J, Davillas A, Demoussis M, et al. Obesity persistence and duration dependence: evidence from a cohort of US adults (1985-2010). Econ Hum Biol 2014;12:30-44.
124. Gordon-Larsen P, Adair LS, Nelson MC, et al. Five-year obesity incidence in the transition period between adolescence and adulthood: the National Longitudinal Study of Adolescent Health. Am J Clin Nutr 2004;80:569-75.

125. Parikh NI, Pencina MJ, Wang TJ, et al. Increasing trends in incidence of overweight and obesity over 5 decades. Am J Med 2007;120:242-50.

126. Williamson DF, Kahn HS, Byers T. The 10-y incidence of obesity and major weight gain in black and white US women aged 30-55 y. Am J Clin Nutr 1991:53:1515S-8.

127. Schneider ALC, Lazo M, Selvin E, et al. Racial differences in nonalcoholic fatty liver disease in the U.S. population. Obesity 2014;22:292-9.

128. Kelishadi R, Cook SR, Adibi A, et al. Association of the components of the metabolic syndrome with non-alcoholic fatty liver disease among normal-weight, overweight and obese children and adolescents. Diabetol Metab Syndr 2009;1:29.

129. Peng L, Wang J, Li F. Weight reduction for non-alcoholic fatty liver disease. Cochrane Database Syst Rev 2011:CD003619. CD003619. doi.

130. Dassanayake AS, Kasturiratne A, Rajindrajith S, et al. Prevalence and risk factors for non-alcoholic fatty liver disease among adults in an urban Sri Lankan population. J Gastroenterol Hepatol 2009;24:1284-8.

131. Lee K, Sung JA, Kim JS, et al. The roles of obesity and gender on the relationship between metabolic risk factors and nonalcoholic fatty liver disease in Koreans. Diabetes Metab Res Rev 2009;25:150-5.

132. Zeb I, Katz R, Nasir K, et al. Relation of nonalcoholic fatty liver disease to the metabolic syndrome: the multi-ethnic study of atherosclerosis. J Cardiovasc Comput Tomogr 2013;7:311-8.

133. Chan WK, Tan AT, Vethakkan SR, et al. Non-alcoholic fatty liver disease in diabetics - prevalence and predictive factors in a multiracial hospital clinic population in Malaysia. $J$ Gastroenterol Hepatol 2013;28:1375-83.

134. Papandreou D, Karabouta Z, Pantoleon A, et al. Investigation of anthropometric, biochemical and dietary parameters of obese children with and without non-alcoholic fatty liver disease. Appetite 2012;59:939-44.

135. Wong VW, Wong GL, Yip GW, Gw-K Y, et al. Coronary artery disease and cardiovascular outcomes in patients with non-alcoholic fatty liver disease. Gut 2011;60:1721-7.

136. Hamaguchi M, Kojima T, Takeda N, et al. Nonalcoholic fatty liver disease is a novel predictor of cardiovascular disease. World $\mathrm{J}$ Gastroenterol 2007;13:1579-84.

137. Fan JG, Li F, Cai XB, et al. Effects of nonalcoholic fatty liver disease on the development of metabolic disorders. J Gastroenterol Hepatol 2007;22:1086-91.

138. Targher G, Bertolini L, Rodella S, et al. Nonalcoholic fatty liver disease is independently associated with an increased incidence of cardiovascular events in type 2 diabetic patients. Diabetes Care 2007;30:2119-21.

139. Treeprasertsuk S, Leverage S, Adams LA, et al. The Framingham risk score and heart disease in nonalcoholic fatty liver disease. Liver Int 2012;32:945-50.

140. Canoy D, Cairns BJ, Balkwill A, et al. Body mass index and incident coronary heart disease in women: a population-based prospective study. BMC Med 2013;11:87.

141. Lu Y, Hajifathalian K, Ezzati M, et al. Global Burden of Metabolic Risk Factors for Chronic Diseases Collaboration (BMI Mediated Effects). Metabolic mediators of the effects of body-mass index, overweight, and obesity on coronary heart disease and stroke: a pooled analysis of 97 prospective cohorts with 1.8 million participants. Lancet 2014;383:970-83.

142. Gruson E, Montaye M, Kee F, et al. Anthropometric assessment of abdominal obesity and coronary heart disease risk in men: the PRIME study. Heart 2010;96:136-40.

143. de Hollander EL, Bogers RP, Boshuizen HC, et al. Influence of calendar period on the association between $\mathrm{BMI}$ and coronary heart disease: a meta-analysis of 31 cohorts. Obesity 2013;21:865-80.

144. Labounty TM, Gomez MJ, Achenbach S, et al. Body mass index and the prevalence, severity, and risk of coronary artery disease: an international multicentre study of 13,874 patients. Eur Heart $J$ Cardiovasc Imaging 2013;14:456-63.

145. Mongraw-Chaffin ML, Peters SA, Huxley RR, et al. The sex-specific association between $\mathrm{BMI}$ and coronary heart disease: a systematic review and meta-analysis of 95 cohorts with 1.2 million participants. Lancet Diabetes Endocrinol 2015;3:437-49.

146. Park YS, Kim JS. Obesity phenotype and coronary heart disease risk as estimated by the Framingham risk score. J Korean Med Sci 2012;27:243-9. 
147. Taylor AE, Ebrahim S, Ben-Shlomo Y, et al. Comparison of the associations of body mass index and measures of central adiposity and fat mass with coronary heart disease, diabetes, and all-cause mortality: a study using data from 4 UK cohorts. Am J Clin Nutr 2010;91:547-56.

148. Peters SA, Huxley RR, Woodward M. Diabetes as risk factor for incident coronary heart disease in women compared with men: a systematic review and meta-analysis of 64 cohorts including 858,507 individuals and 28,203 coronary events. Diabetologia 2014;57:1542-51.

149. Shibata M, Kihara $\mathrm{Y}$, Taguchi $\mathrm{M}$, et al. Nonalcoholic fatty liver disease is a risk factor for type 2 diabetes in middle-aged Japanese men. Diabetes Care 2007;30:2940-4.

150. Kim CH, Park JY, Lee KU, et al. Fatty liver is an independent risk factor for the development of type 2 diabetes in Korean adults. Diabet Med 2008;25:476-81.

151. Yamada T, Fukatsu M, Suzuki S, et al. Fatty liver predicts impaired fasting glucose and type 2 diabetes mellitus in Japanese undergoing a health checkup. J Gastroenterol Hepatol 2010;25:352-6.

152. Sung KC, Kim SH. Interrelationship between fatty liver and insulin resistance in the development of type 2 diabetes. J Clin Endocrinol Metab 2011;96:1093-7.

153. Kasturiratne A, Weerasinghe S, Dassanayake AS, et al. Influence of non-alcoholic fatty liver disease on the development of diabetes mellitus. J Gastroenterol Hepatol 2013;28:142-7.

154. Abdullah A, Peeters A, de Courten M, et al. The magnitude of association between overweight and obesity and the risk of diabetes: a meta-analysis of prospective cohort studies. Diabetes Res Clin Pract 2010;89:309-19.

155. Nyamdorj R, Qiao Q, Söderberg S, et al. BMI compared with central obesity indicators as a predictor of diabetes incidence in Mauritius. Obesity 2009;17:342-8.

156. Rolando L, Byrne DW, McGown PW, et al. Health risk factor modification predicts incidence of diabetes in an employee population: results of an 8-year longitudinal cohort study. J Occup Environ Med 2013;55:410-5.

157. Rodbard HW, Bays HE, Gavin JR, et al. Rate and risk predictors for development of self-reported type-2 diabetes mellitus over a 5-year period: the SHIELD study. Int J Clin Pract 2012;66:684-91.

158. Kodama S, Horikawa C, Fujihara K, et al. Quantitative relationship between body weight gain in adulthood and incident type 2 diabetes: a meta-analysis. Obes Rev 2014;15:202-14.

159. Bell JA, Kivimaki M, Hamer M. Metabolically healthy obesity and risk of incident type 2 diabetes: a meta-analysis of prospective cohort studies. Obes Rev 2014;15:504-15.

160. Guh DP, Zhang W, Bansback N, et al. The incidence of comorbidities related to obesity and overweight: a systematic review and meta-analysis. BMC Public Health 2009;9:88.

161. Emond JA, Patterson RE, Jardack PM, et al. Using doubly labeled water to validate associations between sugar-sweetened beverage intake and body mass among white and African-American adults. Int J Obes 2014;38:603-9.

162. Grimes CA, Riddell LJ, Campbell KJ, et al. Dietary salt intake, sugar-sweetened beverage consumption, and obesity risk. Pediatrics 2013;131:14-21. 